\title{
Pain's Records: An Anthropological Account of Medical Documentation in South Asia
}

\author{
SHAGUFTA KAUR BHANGU
}

\section{Introduction}

The Institute for Pain Management in Kolkata, like other modern institutions, is organised by record keeping. But the central object of its records, pain, presents a fundamental challenge to documentation. Pain is marked by a non-relational attribute that limits attempts to communicate and express it. In her seminal work, Elaine Scarry ${ }^{1}$ has studied the making and unmaking of human worlds by placing bodies in pain at the centre of her analysis. She has explored pain's resistance to objectification and its challenge to linguistic expression and thus, writing. Others have attempted to shift this search for an robjecthood s of pain to its subjective dimensions. Scholars have demonstrated how the relationship between pain and language can be nuanced and expanded while acknowledging the challenges pain poses. A multitude of theoretical frames for understanding pain have been proposed: as an affective category, ${ }^{2}$ affliction, ${ }^{3}$ inscription, ${ }^{4}$ suffering ${ }^{5}$, and as a phenomenological category that isolates and disrupts narrativised experience. ${ }^{6}$ Shifting discourses away from the individual, scholars have also described the intersubjective, juridical, historical and sociocultural milieus in which pain is situated. ${ }^{7}$ However, these writings on pain have shifted away from concerns of pain's medical researchers and practitioners, whose writings are among the discourses that Scarry analyses.

In medical discourse, pain remains a highly ambiguous condition despite being one of the most commonly reported complaints in the clinic. Pain has been at the heart of a number of medical debates such as its status as an robject $<, 8$ methods of measurement of its subjective features ${ }^{9}$ and standardisation of its measurement units. ${ }^{10}$ At stake in these epistemological debates are puzzles of records. How do you manage a condition that you struggle to record? How is pain's evidence constituted? How is treatment performed when pain evades documentation and documentary circulations? ${ }^{11}$

Ethnographic fieldwork at Institute for Pain Management (or the Institute) in Kolkata drew my attention to a proliferation of medical records in clinical production and management of pain. Social studies of medical practice have extensively explored both the role of documentation and decision-making in the face of multiplicity. ${ }^{12}$ There are many similarities between this Institute and the medical centres these scholars have studied. Medical documentation at the Institute, as these ethnographic papers have recorded at other 
centres, is plural, simultaneously enacting a range of epistemic, bureaucratic and normative activities. The problems that this paper aims to address is how documentation practices produce and manage pain as a medical object, the forms documentary multiplicity takes, its materiality and how it enacts pain's therapeutics. Methodologically, the paper leans on Marc Berg and Geoffrey Bowker's analysis of medical records, their temporalities and geographies and the inscriptive practices within which records are situated to trace how medicine's epistemology addresses pain and its challenges. ${ }^{13}$ These challenges are addressed in Kolkata, I argue, by translating a body in pain constituted through artefacts and relationships to a body in pain that exists almost entirely on paper. I trace medical records, their productions and circulations to describe how this translation proves efficacious in the eyes of doctors and patients, and is critical to the management of chronic pain.

\section{Medical Networks: Institute for Pain Management and Documents}

Six months into my fieldwork I visited Manoj Singh's home. Manoj Singh is a chronic pain patient who has been seeking medical assistance at the Institute since 2011. He first visited for chronic low back pain but recently has started suffering from pain in his neck and radiating pains in his left arm. He lived in a jute mill township which was mostly deserted on the day of my visit due to an ongoing strike. His wife, Shakti, welcomed me as I entered their home and immediately sent Manoj to get some milk so she could make tea. Before leaving the home, Manoj walked inside and took his hanging shirt from a peg on the wall. He rushed past us while still buttoning his shirt. Hanging on the peg behind him was a polythene bag labelled "Mars Scan Centre«. When I asked Shakti about the bag, she explained that it contains all his "treatment « documents, ${ }^{14}$ test reports, scans and bills of financial transactions, and then added, "While leaving the home, we find everything in one place«. This encounter drew my attention to polythene bags, their makings and circulations.

Manoj and Shakti were routine visitors of the Out Patient Department (OPD), a weekly clinic where physicians in the Institute attend chronic pain patients. Only people who are insured with West Bengal's Ministry of Labour run insurance scheme are permitted to seek medical help at this centre. There are no consultation or treatment fees involved and all diagnostic and therapeutic procedures are conducted free of cost. Enrolment in this insurance scheme is at a nominal monthly fee which is split between the labourer/employee and employer. Only labour force members who are part of the organised sector are eligible for the scheme. India's organised sector comprises a very small part of its total labour force. ${ }^{15}$ It excludes all workers in the agrarian sector and those who are not officially listed on company rolls and work as daily wage labourers. Thus, a very small subset of India's total labour force is insured. But, given India's vast population, even this fraction of insured labour force comprises of more than 5 million people in West Bengal. Rather than tying up with existing public health infrastructure, Ministry of Labour runs its own network of hospitals for insured members. The Institute for Pain Management is the only publicly funded biomedical pain management centre of its kind in India, and therefore the only one in Kolkata.

In the waiting room of the clinic of this Institute (OPD), we find as many polythene bags of documents as waiting patients like Manoj Singh and his Mars Scan Centre bag. These bags, like files of bureaucratic offices, grow over time, as each visit generates a documentary record. The documents are produced quickly and efficiently as the physicians in the Institute attend between 150 and 200 patients each Tuesday. Many encounters are brief, not longer than 5 minutes, and end with short notes. For others, such as patients in acute pain episodes, physicians write that they be admitted and plan surgical sinterventions - pharmacological or surgical administrations. For chronic pain sufferers, physicians prescribe refills and issue instructions for reviews. For first-time visitors, interactions can last 10-15 minutes and an entire OPD slip may be filled up. Every patient leaves the clinic with an OPD slip, a record prepared by the physician, with a time stamp and an account of the patient's scurrent s status. These OPD slips may advise further investigations, report key information and developments from previous examinations and list therapeutic courses of action. The formation of 


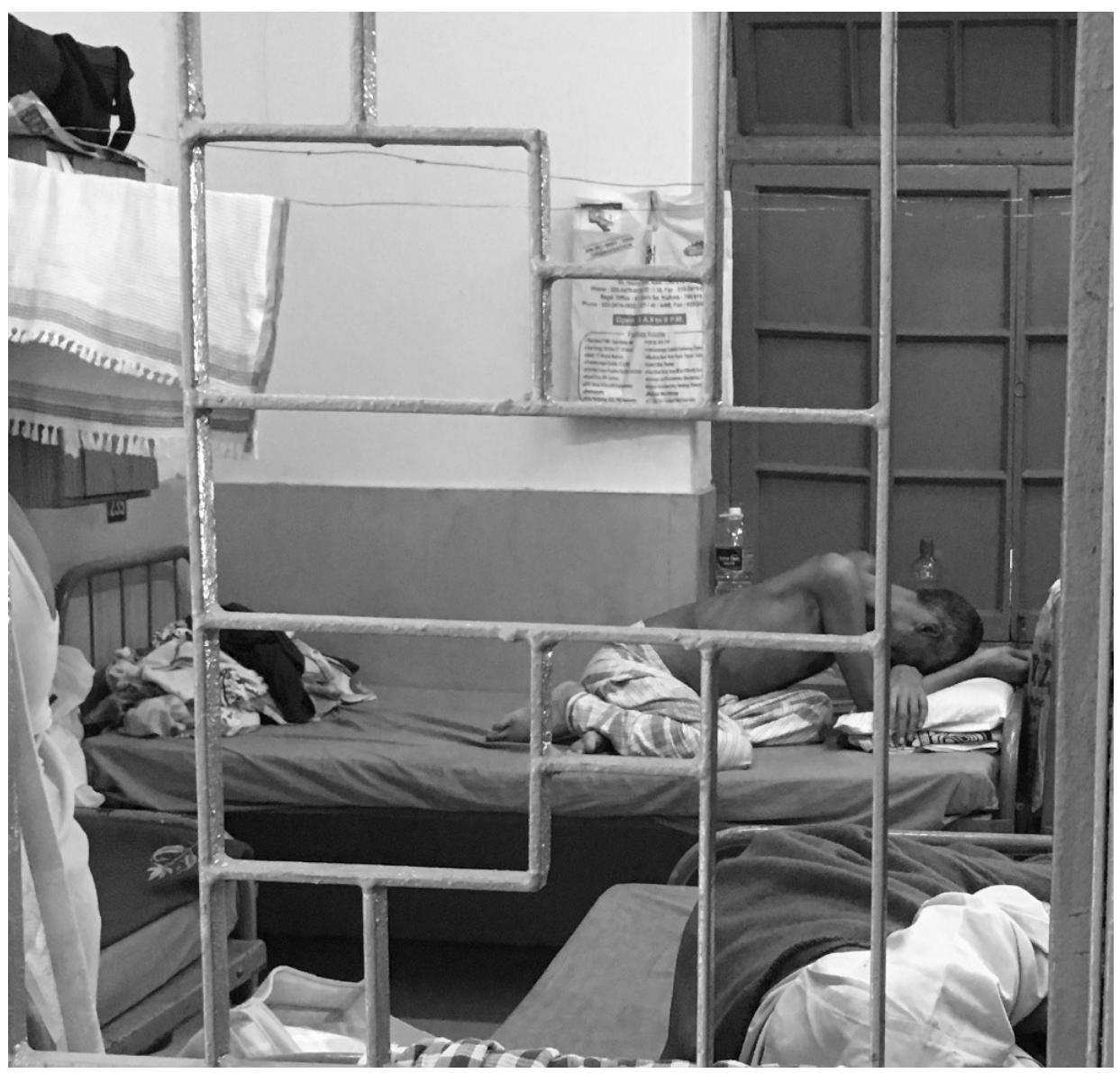

Figure 1: Patient at IPM with polythene bag on the wall behind him. (Source: Author's collection)

one such OPD slip for Manoj Singh is described in the section Crafting Pain's OPD Slips of this paper. This record embeds people like Manoj Singh as chronic pain patients in Kolkata's medical networks (Fig. 2). It leads to the crafting of even more evidentiary documents and records such as X-rays, magnetic resonance imaging (MRI) scans and blood tests. As a prescription slip, it grants Manoj Singh free access to his medication. And, it expedites future clinical reviews by providing a base for gauging improvements and deteriorations in his health.

Apart from this record (OPD slip), situated within polythene bags, are written and typed documents of doctors' notes (referral and discharge slips), haematological and biochemical graphs, X-rays and scan images and also, bills, receipts, insurance documents, claim slips and letters. These artefacts ${ }^{16}$ produce patient accounts. Medically, they produce a patient and his disease as objects of investigation which can then be circulated, fragmented and contrasted. Bureaucratically, these guide movements within the Institute, its parent hospital and the Ministry of Labour insurance network. They constitute Manoj Singh and his disease, and embed him in medical and state bureaucratic apparatus that manage his health and his contribution as a labouring body. But we may also find in these polythene bags, family photographs, coloured graphs and sometimes even analgesic sprays, band aids and medical tapes.

All of these lie together in a disorderly state. They are thrown into the bag and pulled out as and when required. These are not maintained as per medical, legal or bureaucratic protocols, but as records of encounters and meetings between Manoj and the medical regime during the course of his treatment. Since many of these documents are incomprehensible to a lay person and are mostly in English, an unfamiliar language for Manoj Singh, they are only stored, not classified or understood. As Shakti said, "We find everything in one place». Any fragment, any remnant of his pain treatment is carefully 
stored within this bag. Over time, these bags emerge as another shabitat of his pain`, as an assemblage of his medical artefacts. It is a space where accounts of his pain live. These records guide movements within the medical regime and their interactions constitute him as a patient.

Like his phenomenological experience of chronic pain which results in a fragmentation of narrative, temporal coherence and an experiential self, these bags are also indicative of a "struggling along «. ${ }^{17}$ While working through sexperiences` of the homeless mentally ill in Boston, Desjarlais proposed "struggling along " as opposed to "experience «. ${ }^{18} \mathrm{~A}$ phenomenology of Manoj's life with chronic pain and the dispersed and fragmented medical artefacts he collects over the course of his treatment indicates such a struggling along. Over time, his artefacts loosely cohere in one bag and around one name but remain uncoordinated and dispersed invoking different medical centres and indexing different bodily locations (habitats) of his pain. His documentary collectivities are produced in the intersections of a social, cultural and economic milieu of labour, jute mills, state-supported health care and subjective journeys of chronic pain (struggles, suffering and affliction). Each of these records finds its way into the same polythene bag, a repository of records, ordered by only one criterion: a patient's name and so the bag is placed on his person, his peg on the wall with his shirt like an additional piece of clothing that he adorns when traversing the medical world. While these polythene bags accompany patients in visits to the clinic and investigation centres of this Institute, their roles change during hospital admission.

When a patient is admitted, his records are taken out of polythene bags and ordered as per the medical regime's bureaucratic logic. As the polythene bag enters the ward spaces in this Institute, it fragments into its constituent elements. An administrative officer may ask for Manoj Singh's insurance card, a finance officer for his medication bills and a physician for his earlier OPD slips or investigation reports. Once he is admitted, a new temporality and material home for both himself and his medical records - emerges. A hospital admission document grants him a new location: a bed; his polythene bag moves under his pillow or on a peg by the wall or on his bedpost (Fig. 1).
Some documents from the polythene bag find themselves in another institutional location: in a medical file, >Bed Head Ticket ‘ (BHT) or simply >ticket ‘ as it is referred to at the Institute. ${ }^{19} \mathrm{~A}>\mathrm{BHT}$ < is a temporary assemblage that comes into being only for the duration of a patient's admission in the hospital. It is easily recognisable as a blue paper folder with a handwritten number on top. Within it, all srecent test reports and scurrent « doctors' notes are placed since the >BHT، is marked by an immediate temporality. It does not store a patient's entire medical history but documents that assist in crafting his >case and a >diagnosis` each time he is admitted. Test reports which are more than a year old are rarely, if ever, included. A doctor's note, however, may be inscribed for major medical events in patient history such as surgeries, accidents and hospital admissions.

The >BHT , is in sync with a patient through two locations: the institutional location which is the bed in the hospital and the personal location: his/her body (head). This unity, of the bed, head and ticket (BHT), makes it possible to refer to the patient, file and bed by the same number such that when admitted in December 2015, Manoj Singh was simultaneously patient number 23, recorded under file number 23 and placed on bed number 23. This made it possible to refer to him and all matters related to him simply as »23«. Number 23 is a role that may be occupied by other chronic pain patients seeking medical assistance but can be occupied by only one person at a time. Its distinctive feature is that like the polythene bag, the >BHT เ is an individual's and does not speak for more than one ailing body even as it may record multiple ailments. Documents in the 'BHT, are ordered temporally with the most recent document placed right on top and the first admission document placed at the bottom. Predominantly, the 'BHT ongoing therapeutics, his improvements and changing symptoms. The final note in the $>\mathrm{BHT}$ เ that terminates its existence and moves both Manoj Singh and his documentary collections out of the hospital's ward space is the >discharge note written by a doctor. Once a patient is discharged, the $>B H T$ < disaggregates into records that remain in the hospital's record rooms and in patient's records that are carried around in polythene bags. However, the >BHT 
Through the force of law or institutional inquiry, these disaggregated records may be brought together once more to operate as medico-legal accounts. For example, these are called upon and cited at Disability Board meetings to ascertain the sdegree of disability decide compensation amounts (disability payments). They are also used for passing administrative judgement on workplace injuries and damages, and as evidence in legal disputes, both against workplace exploitation and medical malpractice. ${ }^{20}$ Thus, their production in Ministry of Labour institutions results in administering health, labouring capacities and compensations. ${ }^{21}$

Polythene bags, on the other hand, punctuate everyday lives with pain and are mobile repositories (record rooms) of interactions with administrative, medical and legal powers of the state as these accompany patient bodies. Polythene bags circulate among their homes, public transport, administrative and medical offices, hospitals and factories. While a record of each encounter is stored in the polythene bag which enframes a person as a chronic pain patient, we observe an excess of pain that cannot be neatly settled into any one diagnostic or medical artefact. Pain does not remain limited to any one habitat and comes to punctuate the life-world of a person in pain. ${ }^{22}$ As the next section elaborates, it seeps into various locations of his body, his relationships (intersubjective spaces) and his world. ${ }^{23}$ Through an account of Manoj Singh's encounters with the Institute, the section Crafting Pain's OPD Slips describes how pain is addressed by medical epistemology and framed as an object and how a record is produced which translates pain's habitat from body to paper, and finally the section Pain and Multiplicity demonstrates how multiple enactments of pain and a corresponding multiplicity of documents are coordinated and addressed by clinical practice.

\section{Crafting Pain's OPD Slips}

On November 30, Manoj Singh visited his panel doctor seeking medical assistance for pain in his neck and arms. Panel doctors are general physicians of the insurance network who address common ailments but also have the power to suggest hospital admission and specialist attention. Due to large patient volume, the role of panel doctors has shifted to referring patients along. Their clinics have transformed into referral centres. With his referral form, Manoj Singh reached the Institute on December 1.

This section describes how dispersed expressions of his pain were recorded to frame it as a medical object. The section dwells in a physical examination of Manoj Singh conducted by Dr. Pia who observes behaviours and bodily movements, grants them clinical significance and records these as evidence. Bodily conversations of pain gestures ${ }^{24}$ and habitus are presented.25 In "The Logic of Practice«, Pierre Bourdieu writes of habitus as a

"product of history...[It] ensures the active presence of past experiences, which, deposited in each organism in the form of schemes of perception, thought and action, tend to guarantee the >correctness of practices and their constancy over time, more reliably than all formal rules and explicit norms ${ }^{26}$

Such ways of being constitute embodied knowledge, "something that one is «. ${ }^{27}$ Living with chronic pain, certain forms of bodily bearing, behaviours and movements sediment in patient bodies resulting in the formation of pain habituses. These habituses are a product of habit formation, lying at the interstices of social structures and individual presentations of disease (pain). These operate as indices, opening up multiple semiotic analyses, conversations and references. This section dwells on such gestures and habitus and medical semiotics which attempts to decipher these. ${ }^{28}$

Below I present an account of Manoj Singh's visit to the weekly clinic and the making of an OPD slip: On 1 December 2015, patients began arriving at 7 a.m., 3 hours before the clinic of this Institute opens. Each one of them deposited a referral form from his respective panel doctor or an OPD slip from an earlier visit in the spain box`, a cardboard box placed outside the emergency room of the hospital for the patients in this Institute. Today, Manoj Singh is assigned the position of patient number 78, which is quickly scribbled on his referral form by the clinic administrator. At 3 p.m., Dr. Pia calls out, "78! «, as his form has found its way into her allotted set of documents and thus, patients. Shakti and he walk over. He moves a little stiffly, rarely turning his neck and instead shifting his torso to face someone or shift his 


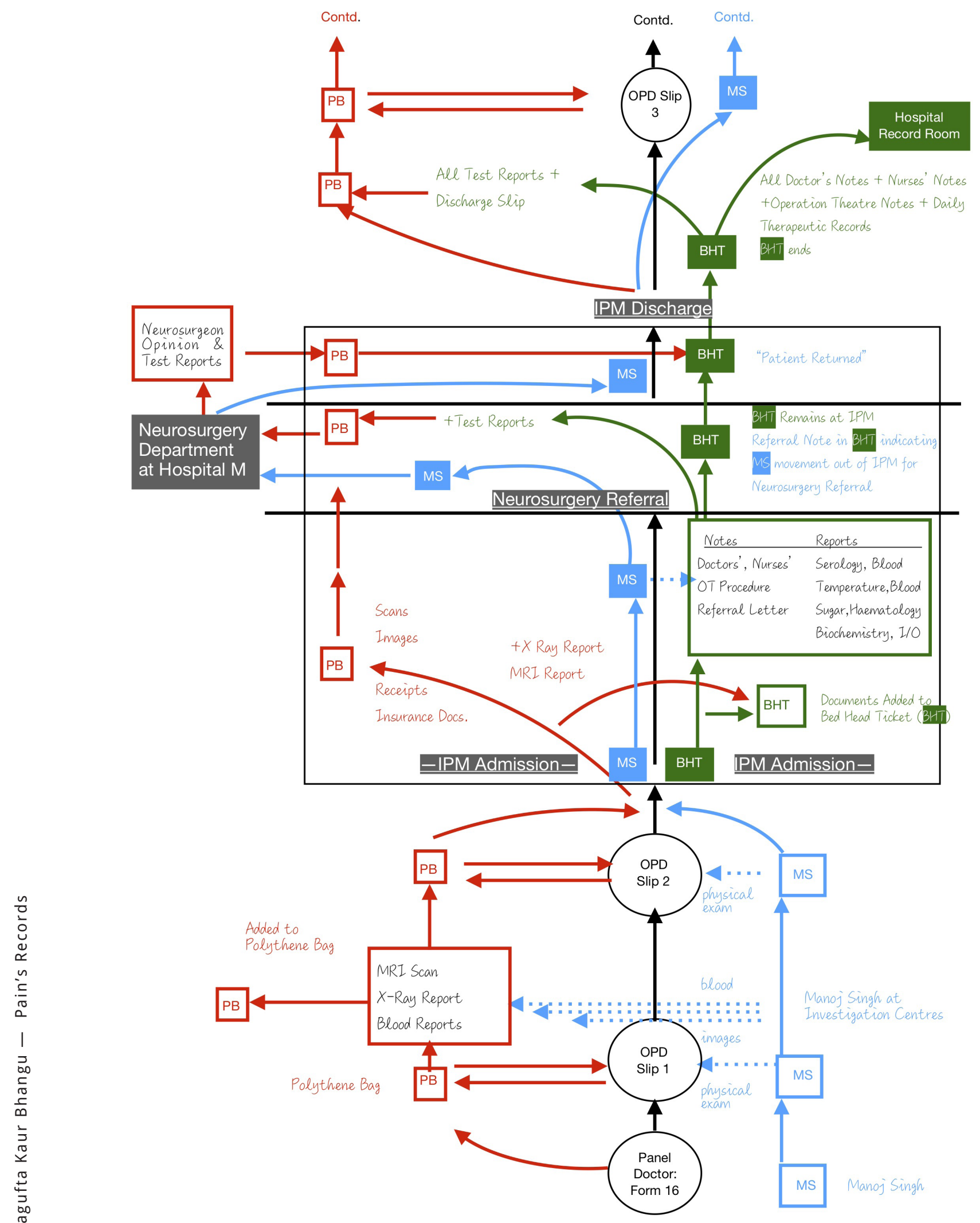

Figure 2: Flow chart representing life course of Manoj Singh's pain documents. 
orientation. Over a 15 minute interaction, Manoj Singh answers and Dr. Pia takes notes, occasionally looking up at him while Shakti stands on his right, holding a polythene bag of documents.

Dr. Pia: "What is the problem?»

Manoj Singh responds while holding his left arm: „We've been here earlier. I had pain in my back. Now, neck and arm are giving me trouble«.

Dr. Pia writes down, »cervical pain. Lf sided. Radiculopathy (Left hand)« and examines him. She stands up, holds his head and rotates it from side to side. She stops when she either sees him wincing or hears him cry out. Under one such movement, Manoj Singh jerks forward and holds the edge of the table. She stops. Next, she tilts his head backwards, then to the left and using the palm of her hand presses downwards. He winces. She repeats, tilts his neck backwards and to the right. He sits unaffected. She sits back down and writes, "Increases with cervical joint movement (Range of Motion test). Increases with sitting «.

She enquires about the durational history of his pain and about any accident or injury that he may have suffered in the past. He describes how the pain had slowly begun 2 years ago and then started interfering with his ability to work and to move around. "When I go to buy vegetables, I can’t carry the load «. ${ }^{29}$ While pain has crept into his phenomenological accounts, it has also altered his life-world. It dwells as much in the relationships and roles he plays, as a husband and bread winner for his family, as it does in his physical body. Yet, for her records, Dr. Pia notes pain's physiological markers alone.

She asks if he has received any treatment for pain. He mentions his lower back pain history. She writes it down and asks for his documents from that hospital admission. Shakti reaches into the polythene bag and pulls a few documents out. She hands them over and Dr. Pia searches for the ones she needs. "How is your back pain now?«, Dr. Pia asks glancing through the discharge slip from his last hospital admission. She notes a cervical procedure that was performed 2 years ago but is uncertain of the exact intervention. Before she can dwell on this, Shakti replies, "He's much better now. After getting treated from doctors at this institute, he's not had any trouble. Because of this, we asked the panel doctor to refer us to you".
Writing about his earlier treatment, Dr. Pia instructs Manoj Singh to stand up, place his hands on his waist and bend forwards and then backwards. He resists moving forward. He winces when she tries to force him. She writes, "Increases on bending forward «.

She asks if he has been subjected to any medical investigations such as imaging tests, "Have you got any photographs of your neck? «30

Manoj: "No madam»

She replies, "You'll have to get a photograph. Get a photograph and come back to us, then we'll see".

Next, she guides him to the corner of the room where the physical examination table is placed. She tells him to, "Lie down«. She asks him to turn over and lie on his stomach. She asks him, "Where does it hurt? " as she touches and presses with her fingers various parts of his lower back, hips and buttocks. He tells her it is hurting in the entire lower back. She also checks for muscle tenderness, muscles that give way more easily than others and offer lesser resistance in comparison with those around it and for any lumps or trigger points that may exist in the muscle. ${ }^{31}$ She does not find any of these. She asks him to turn around and face up. He complies. She does not watch his face to see his reactions and continues examining him. She pauses if she hears him cry out or if she feels the muscles she's examining flinch or stiffen. Through touch and sound, Dr. Pia and Manoj Singh proceed. She performs a number of physiological tests noting his responses and then sits down to write. ${ }^{32}$ At the end of the consultation, she asks them to return with a "photograph" and hands them the OPD slip with her notes. Shakti places this OPD slip (Fig. 3) with other documents in the polythene bag.

\section{Inscriptive Conversations: From Habitus to Medical Record}

As this encounter demonstrates, pain's presence, nature and intensity are ascertained by physicians at the Institute through pain's inscriptions and signs available on patient bodies. In the moments with Manoj Singh, Dr. Pia notes, like me, how he walks stiffly towards us and turns his torso to face someone or shift his orientation. The distinction between our awareness is a disciplinary one. She is observing him approach 


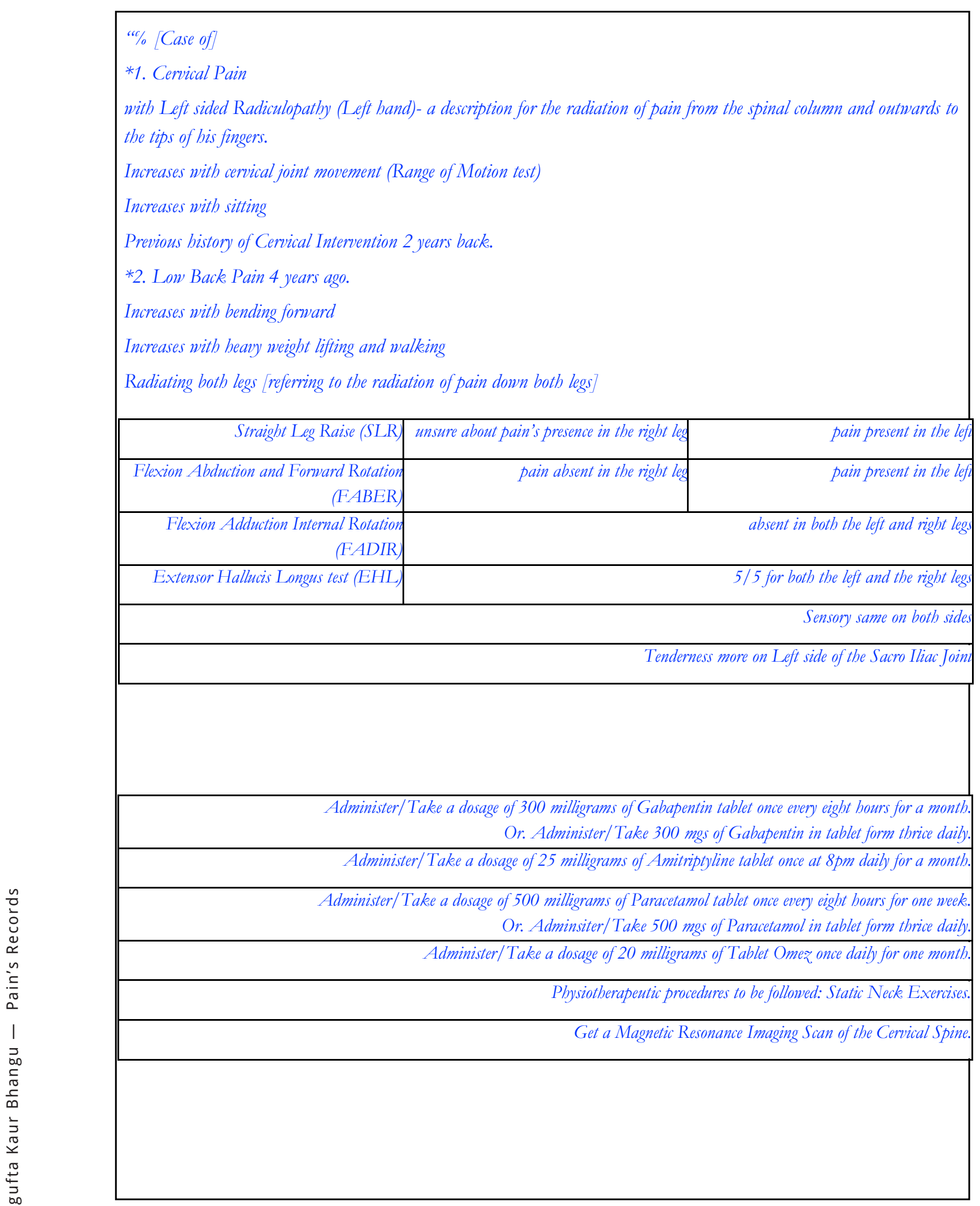

Figure 3: Transcription of Dr. Pia's writing on Manoj Singh's OPD slip. 
through a physiological and medical lens while my readings of his bodily bearing employ theoretical frames like Marcel Mauss's and Pierre Bourdieu's concept of shabitus`. Dr. Pia, on the other hand, relies on her medical training in occupational diseases and physical medicine rehabilitation. She combines this with an acute awareness of bodily bearing and bodily semiotics for understanding pain. Resource poverty at this Institute has transformed the physical examination into a critical diagnostic exercise and as Dr. Pia performs it, she produces from her clinical observations evidence of pain's presence and identifies a habitat of pain in Manoj Singh's physiological body. Both of us take note of his altered bodily shabitus, and recognise in it the presence of pain as a product of years of heavy load lifting and living with chronic pain.

This overlapping interest in the triangulation of pain, habitus (bodily bearing, gait, gestures) and habitat lies at the beginning of my engagement with Dr. Ghosh, head of the pain management institute in Kolkata, and his team. I first met Dr. Ghosh at a national pain conference in 2015 where he presented a paper titled "Gait Analysis and Chronic Pain«. On his powerpoint display, he did not begin with X-rays or computed tomography (CT) scan images like the physicians before him, but with photographs of people at work such as a rickshaw puller and a daily wage labourer carrying heavy load. Referring to these images, he demonstrated on his own body the physiological units at work for different bodily postures and movements. He stressed on accentuated bodily bearing of the labourers and thus, drew a connection between a labouring body and an altered habitus..$^{33}$ The alterations in habitus, in these cases, are a result of sedimentation of bodily postures and movements performed for years in heavy extractive manual labour. From these shifts, he drew out a story of pain's presence retroactively. In acknowledging pain's presence in altered habitus, he correlated a life of pain co-present with a life of labour and labouring gait patterns. He fused through his description the act of seeing altered gait with witnessing hurting bodies. Once alerted to the importance of gait, he began to analyse it and mine it for diagnostic purposes. By breaking gait into its constituent elements, he spatialised gait and pain in the body as movements of specific parts and described a (habitats). ${ }^{34}$ Thus, he described how a pain habitus can be translated to rbodily habitats - first, a location where pain dwells and second, a location where therapeutics may be inscribed. ${ }^{35}$ Like gait analysis, the physical examination also tries to spatialise pain and enframe it in habitats by recording where and when it appears, and also how it changes (increases or decreases) with respect to specific movements and gestures.

While gait analysis is largely a visual investigation, the physical examination is a tactile and conversational investigative technique. Touch and sound are translated into pain's presences and absences. ${ }^{36}$ In the physical examination, Dr. Pia's clinically trained expert habitus interacts with Manoj Singh's hurting body. She attends to a bodily semiotics of pain which is marked by gestural responses and cries. By exploring the range of his movements and limits that pain introduces, his bodily disposition and discomfort is apprehended. His cries and gestures are observed as sevidence and conclusions are made about pain. She attends not only to pain and its bodily signs (shifts in habitus) but also its locations that he is in pain shere (habitat). These intercorporeal transactions between painful and expert habituses produce pain from subjective confines and bring it to an intersubjective space. ${ }^{37}$ In the intersubjective space of the physical examination, pain is shared such that Manoj Singh's cry of pain is simultaneously seen, heard and felt by Dr. Pia.

\section{Bearing Witness, Recording Evidence}

While exploring bodily signs of pain, Dr. Pia has simultaneously noted these thus crafting a medical narrative of pain and its bodily habitats on an OPD slip. Her writing is a record of recognition and a spatialisation of pain in his body and on paper. Shorthand phrases like, »SLR+ in L (Straight Leg Raise test positive in Left leg)« in medicine's technical language produce a physiological narrative of pain from a phenomenological one. A series of such statements are inscribed on the OPD slip, as revidencer detailing pain's presence, manifestations and effects. The section Introduction described the difficulties pain poses to medical knowledge production (to objectification, narrative and measurement) but curiously, everyday clinical work in Kolkata is not 
marked by anxiety or doubt about pain's knowability. In fact, we encounter the word "pain « frequently in Dr. Pia's writings. It is in her opening comment on the OPD slip, »\% [Complaint/of] 1. Cervical Pain«. Later in the document, we also come across a chart of pain's absences and presences collected through physiological tests.

In her work, she combines the two roles of witnessing and observing pain. Her expertise is what translates her witnessing of pain to a clinical significance such that her writings on the OPD slip provide evidence to constitute pain as a medical object. This stringing together of pain's evidence and therapeutics on a single page demonstrates a second inscriptive conversation. From conversing habitus of the physical examination, we now observe different components of a written document in conversation as diagnostic and therapeutic inscriptions interact in medical records. Since medical work coordinates between body and record, as workings of the BHT demonstrated in Medical Networks: Institute for Pain Management and Documents, these therapeutic statements are inscribed not only on OPD slips but also on patients' bodies. ${ }^{38} \mathrm{Dr}$. Pia's provisional diagnosis and prescription of future therapeutic acts and investigations are an acknowledgement of Manoj Singh's current suffering, and are a response to his call of pain. She responds as a medical expert, not with a caress or a soothing comment, but one in which she inscribes therapeutic instructions on his OPD slip and subsequently, his body. She prescribes medications and physiotherapy to address pain's evidentiary conditions which she has listed on the same document. As she recognises pain's writing in his body, she writes in his records. Although she records a spread of pain all over his body, she concludes the document with the following provisional diagnosis, "Cervical Myelopathy with Prolapsed Intervertebral Disc Disease " taking cognizance of the specific ailment that he and Shakti voice, »I had pain in my back. Now, neck and arm are giving me trouble«. The crafting of such an OPD slip is at the heart of medical work as a number of scholars have demonstrated. But the difficulty in divorcing patients' accounts from their pain implies the making of these records hinges upon physicians bearing witness and observing bodily signs of pain (gestures and habitus) as Dr. Pia does.
While Dr. Pia bears witness to Manoj Singh's pain, it is her medical expertise which grants it clinical recognition and provides an account of its spread and manifestation in 'medical terms (i.e. terms which activate the medical archive and its knowledge of the body). By situating pain on a document like the OPD slip, pain gains clinical and scientific recognition as a pathological object. It reveals how a material home is crafted for pain to inhabit such that medical practitioners, institutions and knowledge making regime can share the patient's painful world and grant legitimacy to his experience. Once recorded on a document, Manoj Singh's scaser and his pain become transportable and sharable. With this OPD slip begins the story of pain's medical inscriptions, and diagnostic and therapeutic administrations since Manoj Singh and his pain are now available as objects of knowledge which can be interrogated and understood across sites of the medical regime. Referrals and targeted physiological investigations are enabled. In fact, the generative and enacting qualities of such a medical document propels Manoj Singh through the medical bureaucracy producing multiple records across sites and specialisations. ${ }^{39}$ As subsequent encounters between Manoj Singh and the medical regime shall demonstrate, the OPD slip remains a foundational document in the course of his treatment and along with subsequently produced medical records, it provides avenues for understanding, assessing and performing therapeutics. It is in records like these that pain is enframed biomedically.

\section{Pain and Multiplicity}

Inherent in a record like the OPD slip are future acts of medical documentation. After the OPD slip, Manoj Singh is scanned at a private diagnostic centre that produces a MRI scan and report. As he visits the clinic with this new report, he meets with another pain physician - Dr. Bijoy. This meeting results in a second OPD slip that refers him to more physiological testing. As medicine tries to record various facets of his pain experience, multiple medical documents are produced (Fig. 4).

These are recordings from different medical sites but each presents a facet of his pain. As evidentiary documents produced by multiple experts, these are translations from a body in pain to records of pain. 


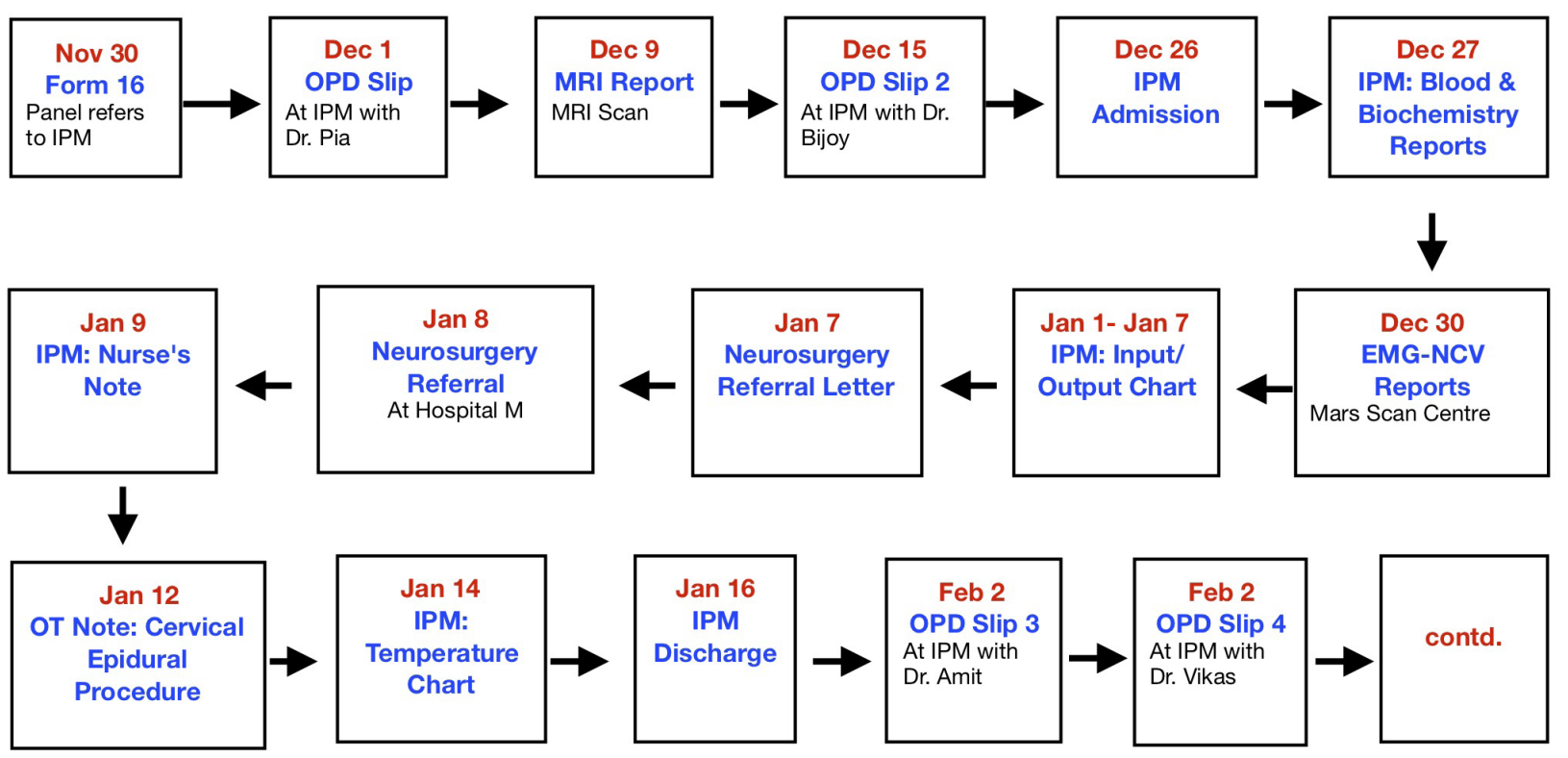

Figure 4: Timeline of Manoj Singh's documentary productions.

Each new document is added to his polythene bag. In these papers, we witness the formation of a sfile-selfı, a concept proposed by Roma Chatterji in her paper, "An Ethnography of Dementia«, which she describes as a discursive object that emerges in the clinic between what is written and in expert discussions around such writings. ${ }^{40}$ The "file-self" constitutes a patient "as an object of knowledge " and the workings of his disease are "divided up into different functions that are to be handled by specialists «. ${ }^{41}$ We observe fragmented constitutions of the person along medical specialisations making a scase which is "thought to be coordinated by the steam approach so that the patient can be reconfigured as a $>$ whole person $\ll$ « ${ }^{42}$ As she traces the institutional career of a patient with dementia, she notes how deterioration of a self and transfer of practices of care from familial networks to the medical regime occur. Under these circumstances, the patient's experiential self can only be recorded through sother and in this case, medical voices. Custodial nature of medical institutions "presupposes a certain perspective on the individual - a somewhat behaviouristic one « ${ }^{43}$ This perspective privileges "a systematic classification of the person in terms of his or her >functions « $"{ }^{44}$ When various "specialists concerned with different aspects of we would call his >file-self $«{ }^{45}{ }^{45}$ In Kolkata, when such documents are collected in a polythene bag, a number of similarities are observed with Chatterji's files the constitution of persons as objects of knowledge, a fragmentation along specialisations, attempts at coordination by the steam of the patient's experiential self through medical voices. However, the polythene bag fails to produce a narrativised 'file-self ' of Manoj Singh and instead produces a fragmented one mirroring pain experiences (or struggles). ${ }^{46}$ Although collected in a single polythene bag or >BHT<, the documents do not cohere. Instead, these bags are collections of documents, which operate as mobile repositories for medical bureaucracy and an item of clothing for Manoj Singh. As repositories, these polythene bags enable mobilisation of Manoj Singh's case across medical sites. The bag works as a register of investigation like his body. Questions in the clinic are posed to him and his documents and as each specialist inscribes therapeutic acts, it is hoped that taken together the documents will address all the limitations and difficulties pain has introduced. ${ }^{47}$

Despite regular contact with the medical regime and production of multiple documents recording Manoj Singh's pain and prescribing therapeutics, his pain worsens. On December 26, he is admitted at the 
Institute which is accompanied by the allocation of a >BHT 23، and a hospital bed (Number 23). His current medical records starting with Dr. Pia's OPD slip and up until his admission advice by Dr. Bijoy shift to the BHT. New documents continue to be added to this BHT: blood report on December 27, biochemistry report on December 27, a haematology report on December 29 and an Electromagnetic Nerve Conduction report on December 30. As medical work aligns these documents with manifestations in a body and life, a unity is produced between pain's inscriptions in the documents and its inscriptions in the body. The work of medical writing is to produce and perpetuate this unity between Head (body) and Ticket (medical artefact). During Manoj Singh's hospital admission, medical records are stored in >BHTs These records include haematological, biochemical, neural and biophysiological accounts of him with multiple diagnostic interpretations and therapeutic prescriptions. This interpretive multiplicity lies at the heart of his prolonged contact with the medical regime and a lack of improvement of his pain as until January 11 Manoj Singh did not undergo any specialised pain management procedure or intervention and was only being treated with a routine course of pain medications. ${ }^{48}$ He was referred to numerous diagnostic centres and medical specialists. The documentary multiplicity which ensued was a result of multiple diagnostic attempts across medical sites in which each document recorded a different provisional diagnosis (Fig. 5). At stake in the varying diagnoses of pain was a difficulty in identifying pain's habitat in his body (location) where therapeutics should be focused. To arrive at a clear diagnosis for Manoj Singh's pain was already a difficult task since he presented with a spread of pain all over his body. On his first OPD slip, Dr. Pia proposed "Cervical Myelopathy with Prolapsed Intervertebral Disc Disease with Radiculitis«. She focused on his neck pain as the current cause of his suffering but a careful reading of his listed provisional diagnoses reveals that they are all in agreement about the bodily region and habitat of his pain: "neck «, "cervical « feature in every one of them. It is the precise manifestation of his pain's location (habitat) that is under debate. Is it a radiating pain (radiculopathy)? Or a fused joint (arthropathy)? Or is it a spinal disc injury (protrusion or degeneration)?
Irrespective of the diagnosis the physicians settle upon and the disease category they enact, it is evident from this documentary proliferation and anxious diagnostic search that pain is apprehended only in a fragmented form in each document. This multiplicity captures different possibilities of Manoj Singh's neck aches as pain is enacted differently in each documentary formation. Annemarie Mol recognises multiplicity as a fundamental feature of medical practice in which coordination occurs by contrasting and combining various evidentiary productions. ${ }^{49}$ However, this paper has demonstrated the myriad ways in which pain pushes against medical epistemology. First, it is very difficult to exclude a patient's responses and his/her self-report in the diagnostic and therapeutic processes. The medical encounter begins and is shaped by patient accounts. Second, the acts of translation that occur in pain are different from those that occur in atherosclerosis. Doctors rely, as the paper has demonstrated, on patient voices, gestures and habitus to constitute evidence of pain. Third, pain evades quantification and this changes the coordinating efforts that Mol describes. Very few productions of pain are through quantifications. Note the curious absence of numbers on the OPD slip except at one point which is for EHL test which is a strength test. In the absence of quantifications, coordinating diverse medical practices becomes difficult. Further, the techno-scientific productions (scans, images and reports) are hardly conclusive for pain. At best, they can be mobilised by doctors for interpretation as signs of pain's presence but not for understanding its nature. So even though multiple records of pain have been crafted, it is this multiplicity which challenges coordination as it pulls Manoj Singh in different therapeutic directions and possibilities. ${ }^{50}$ We observe the makings of a paper subject where diagnosis, though multiple, is not the goal of medical practice. Instead, physicians are searching for pain's habitats so that therapeutic responses can be inscribed. A search for an effective therapeutics in the face of this documentary multiplicity compelled his physicians to refer Manoj Singh to the Neurosurgery department on January 8. They hoped that another specialist may reveal a conclusive diagnosis and advise an effective therapeutic solution.

As we entered the neurosurgeon's clinic on January 8 , we found two neurosurgeons sitting on either side of 


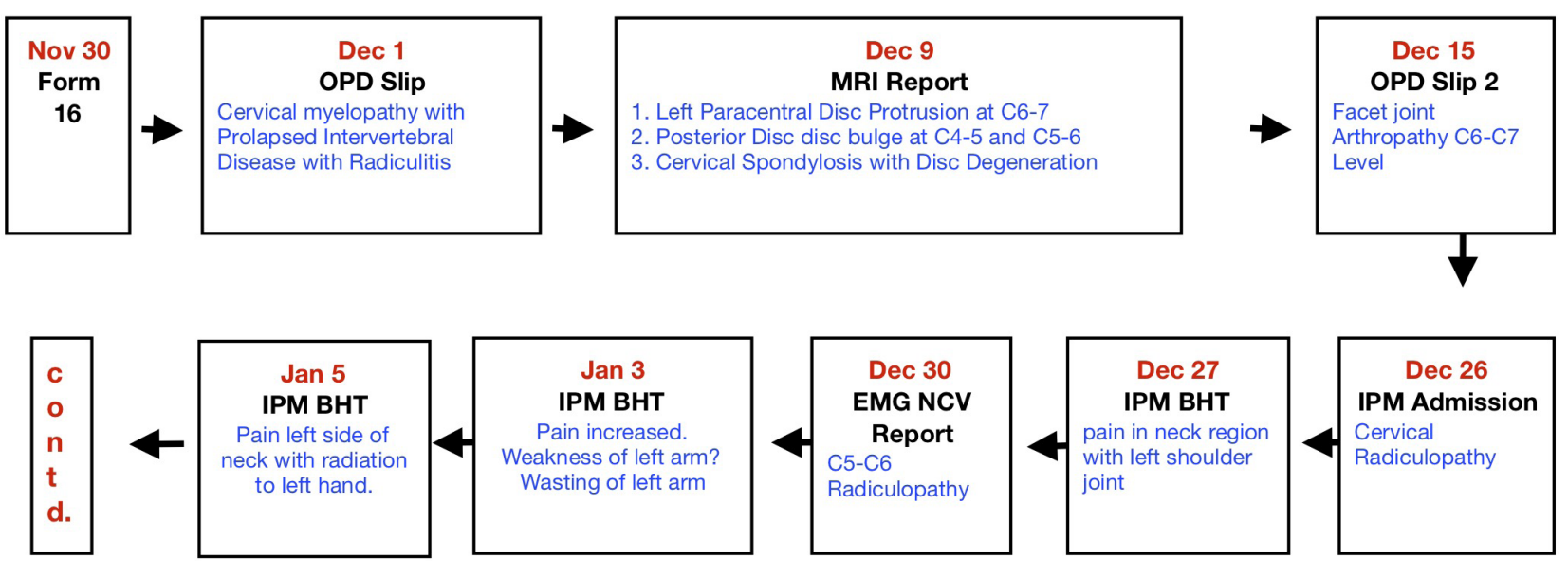

Figure 5: Timeline of Manoj Singh's changing diagnoses.

a large desk. The surgeon across the table was already seeing a patient. When the neurosurgeon on our side of the table was ready for us, he held out his hand without looking at any of us. Manoj Singh gave him the sreferral letter Dr. Pia wrote for him, an introductory letter for her patient (presented below).

To,

The Medical Officer Specialist

M. Hospital

(Through proper channel) Date - 7/1/16

Sir/Madam,

This 49 yrs old male patient presented with Left sided neck pain with Radiation to left hand along with Left arm movement restriction. Got Admitted in the Institute.

On examination $(O / E)$,

Left upper limb

- Deltoid weakness

- Range of Motion of Shoulder joint - restricted (all)

- Tenderness over left upper trapezius muscle Investigations:

NCV - Normal amplitude, conduction velocities of median and ulnar nerve

EMG - Denervation pattern MUPs over left deltoid

Biceps \& supraspinatus muscles at sub maximal volitions.

MRI of Cervical Spine:

- C6-C7 paracentral disc (Left) protrusion

- Central canal stenosis
- C4-5 and C5-6 level disc bulge

- Cervical spondylosis with disc degeneration

Kindly give your valuable opinion whether $p t$. needs further surgical interventions \& do the needful.

Patient Particulars Yours faithfully,

Manoj Singh/49 years Pia M, General Medical Officer, The Institute

The neurosurgeon glanced through the letter and asked, "Photo? «. Shakti handed him the MRI scan. The neurosurgeon looked at the scan and fairly quickly remarked, "There will be a surgery. Come next Friday. Bring someone from the family. It'll take about 3-4 days " However, before he could finish, Manoj Singh said, "I don’t want a surgery».

With a short acknowledgement, »Hmm!«, the physician quickly prescribed some medicines on the Neurosurgery OPD slip and handed the document to Manoj Singh before another word could be said. We were ushered out of the door by his attendant. We were there for less than 2 minutes and he had not once looked up at any of us.

Since the referral letter was written 6 weeks into Manoj Singh's time at the Institute, it contained far more information as a medical document than the first OPD slip discussed in the paper. The referral letter is a collectivised, though fragmented, account of medicine's efforts at apprehending pain. We encounter a sfile-self , which is a list of physiological signs of pain and its medically produced evidence. As a collection 
of inscribed statements, it demonstrates the trials and tribulations Manoj Singh has undergone in his search for treatment. It is a habitat of his pain in a double sense. It contains various artefacts produced over the course of his struggle with pain (pain records). Second, it lists various evidentiary translations from his body to documents of pain (signs of pain). And it appears this act of translation has reached an end. On the one hand, the Neurosurgeon does not feel the need to examine or even glance at Manoj Singh for making as important a therapeutic decision as surgery. He finds sufficient information in the referral letter to understand his case. On the other hand, the same document is a result of an impasse at the Institute. It has been inscribed because of an ever-increasing multiplicity that can no longer be coordinated, and which impeded therapeutic decisionmaking. The referral letter to neurosurgery department is an attempt towards a therapeutic solution. It has moved Manoj Singh's case from pain physicians at the Institute to Neurosurgery department at Hospital M. It is hoped that this transfer to a new medical site can propel the production of new knowledge in his case.

While mirroring the transportability of a scientific document, medical documents are peculiar. ${ }^{51}$ Their separation from the subject they are recording can never be complete. We observe this in Manoj Singh's case as he accompanies his records in every instance. The co-presence of these two - body and file - makes re-examinations and re-evaluations possible and allows for multiple diagnoses to emerge as we observed in his case. Each time a physician explores Manoj Singh's body, the diagnostic category alters (Fig. 5). While it is true that medical documents, like Latour's scientific documents, carry their own referents, the movement of bodies along with medical records (BHTs, OPD slips, referral letters, polythene bags) makes this referent open-ended. We encounter multiple selves of hurting bodies, multiple inscriptions of pain in medical records. Yet, each holds clinical significance and cannot be easily dismissed. As rexpert witnesses`, writings and pain productions of each physician are medical evidence. In this multiplicity, consulting with a neurosurgeon became an essential step in his therapeutic journey but this search maintained the impasse the physicians in the Institute had hoped to circumvent as Manoj Singh refused surgery. Faced with his refusal and with »neck» or "cervical" as the only common link in his varied diagnoses, the physicians in the Institute opted for a Cervical Epidural procedure, a procedure in which a drug (anaesthetic solution) is administered in the cervical region which results in a generalised numbing and anaesthetising effect in the neck and hence, on pain. After performing the procedure on January 12, Manoj Singh's pain reduced and he was discharged 4 days later on January 16.

\section{A Letter for the Institute}

As his pain reduced in the last few days of his hospital admission, Manoj Singh along with other patients wrote a letter. This letter, addressed to the Hospital Superintendent, was a letter of appreciation for the physicians in the Institute. In particular, they credited the doctors in this Institute for "understanding their pain « and for continuing to provide therapeutic assistance in the face of a disease that plagues them. This letter was the only documentary record produced during his hospital admission which did not record him as a bodily fragment in the institution and is not an account of his subjection to a bureaucratic or medical force. Instead, produced after a successful therapeutics, it is the reverse. As its author, it expresses his gratitude not as a disaggregated and dispersed subject but one with a unified voice. This return of voice from medical records to a letter could only be possible due to a successful therapeutics. As a chronic pain patient, Manoj Singh knew that his pain will return and he will be seeking medical assistance soon but he wanted to "place on record " his appreciation. ${ }^{52}$ Since the letter was addressed to the Superintendent of the hospital, it became part of institutional record. Unlike institutional documents that comprise predominantly of forms and other preformatted records, this handwritten letter about personal experience was as unique a record as its authors. This letter was the only one of its kind during my fieldwork and thus, a very rare occurrence for an institution that caters to thousands of patients and produces thousands of documents each year. 
1 Elaine Scarry: The Body in Pain. The Making and Unmaking of the World, Oxford 1985.

2 Veena Das: Language and Body. Transactions in the Construction of Pain, in: Veena Das: Life and Words. Violence and Descent into the Ordinary, Berkeley 2007, pp. 38-58; Robert R. Desjarlais: Body and Emotion. The Aesthetics of Illness and Healing in the Nepal Himalayas, Philadelphia 1992, pp. 90-134.

3 Veena Das: Affliction. Health, Disease, Poverty, New Delhi 2015; Jean E. Jackson: Camp Pain. Talking with Chronic Pain Patients, Philadelphia 2000.

4 Talal Asad: Notes on Body, Pain and Truth in Medieval Christian Ritual, in: Economy and Society 12/3 (1983), pp. 287-327.

5 Arthur Kleinman / Veena Das / Margaret M. Lock (eds.): Social Suffering, Berkeley 1997; Veena Das: Critical Events. An Anthropological Perspective on Contemporary India, New Delhi 1995; Arthur Kleinman: Social Origins of Distress and Disease. Depression, Neurasthenia and Pain in Modern China, Yale 1988.

6 Robert R. Desjarlais: Shelter Blues. Sanity and Selfhood Among the Homeless, Philadelphia 1997; Drew Leder: The Absent Body, Chicago 1990.

7 Julie Livingston: Improvising Medicine. An African Oncology Ward in an Emerging Cancer Epidemic, Durham 2012, pp. 119-151; C. Jason Throop: Suffering and Sentiment. Exploring the Vicissitudes of Experience and Pain in Yap, Berkeley 2010; Georges Canguilhem: The Living and its Milieu, in: Paola Marrati / Todd Myers (eds.): Knowledge of Life (trans. Stefanos Geroulanos \& Daniela Ginsburg), New York 2008, pp. 98-120; Susan Greenhalgh: Under the Medical Gaze. Facts and Fictions of Chronic Pain, Berkeley 2001; Das: Critical Events; Mary-Jo Delvecchio-Good et al. (eds.): Pain as Human Experience. An Anthropological Perspective, Berkeley 1992; Linda C. Garro: Chronic Illness and the Construction of Narratives, in: Mary-Jo Delvecchio-Good et al. (eds.): Pain as Human Experience, Berkeley 1992, pp. 100-137; Byron J. Good: A Body in Pain, in: Delvecchio-Good et al. (eds.): Pain as Human Experience, Berkeley 1992, pp. 29-48; Asad: Notes on Body; Mark Zbrowski: People in Pain, San Francisco 1969; Mark Zbrowski: Cultural Components in Response to Pain, in: Journal of Social Issues 8/4 (1952), pp. 16-31.

8 Jane Scott / Edmund C. Huskisson: Graphic Representation of Pain, in: Pain 2 (1976), pp. 175-184; Ronald Melzack: The McGill Pain Questionnaire. Major Properties and Scoring Methods, in: Pain 1 (1975), pp. 277-299; Ronald Melzack / Warren S. Torgerson: On the Language of Pain, in: Anaesthesiology 34 (1971), pp. 50-59; Henry K. Beecher: Measurement of Subjective Response, New York 1959; Henry K. Beecher: Experimental Pharmacology and the Measurement of the Subjective Response, in: Science 116 (1952), pp. 157-162; Arthur S. Keats / Henry K. Beecher / Frederick C. Mosteller: Measurement of Pathological Pain in Distinction to Experimental Pain, in: Journal of Applied Physiology 3/1 (1950), pp. 35-44.

9 Marianne Jensen Hjermstad et al.: Studies Comparing Numerical Rating Scales, Verbal Rating Scales, and Visual Analogue Scales for Assessment of Pain Intensity in Adults. A Systematic Literature Review, in: Journal of Pain and Symptom Management 41/6 (2011), pp. 1073-1093; Yoshio Nakamura / C. Richard Chapman: Measuring Pain. An Introspective Look at Introspection, in: Consciousness and Cognition 11 (2002), pp. 582-592; Michelle Briggs / José S. Closs: A Descriptive Study of the Use of Visual Analogue Scales and Verbal Rating Scales for the Assessment of Postoperative Pain in Orthopedic Patients, in: Journal of Pain and Symptomatic Management 18/6 (1999), pp. 438-446; Edward C. Huskisson: Measurement of Pain, in: The Lancet 2 (1974), pp. 1127-1131; John M. Woodforde / Harold
Merskey: Some Relationships Between Subjective Measures of Pain, in: Journal of Psychosomatic Research 16/3 (1972), pp. 173-178.

10 Noémi Tousignant: The Rise and Fall of the Dolorimeter. Pain, Analgesics and the Measurement of Subjectivity in Mid Twentieth Century United States, in: Journal of the History of Medicine and Allied Sciences 66/2 (2011), pp. 145-179; Henry K. Beecher: Pain. Controlled and Uncontrolled. Rejoinder to Dr. Hardy, Dr. Wolff and Miss Goodell, in: Science 117 (1953), pp. 166-167; Harold G. Wolff / James D. Hardy / Helen Goodell: Pain. Controlled and Uncontrolled, in: Science 117 (1953), pp. 164-165; Harold G. Wolff / James D. Hardy / Helen Goodell: Studies on Pain. A New Method for Measuring Pain Threshold. Observations on the Spatial Summation of Pain, in: The Journal of Clinical Investigation 19 (1940), pp. 649-657.

11 Annemarie Mol: The Body Multiple. Ontology in Medical Practice. Durham 2002.

12 Ramah McKay: Documentary Disorders. Managing Medical Multiplicity in Maputo, Mozambique, in: American Ethnologist 39/3 (2012), pp. 545-561; Alice Street: Artefacts of Not-Knowing. The Medical Record, the Diagnosis and the Production of Uncertainty in Papua New Guinean Biomedicine, in: Social Studies of Science 41/6 (2011), pp. 815-834; Mol: The Body Multiple; Marc Berg / Geoffrey Bowker: The Multiple Bodies of the Medical Record. Toward a Sociology of an Artifact, in: The Sociological Quarterly 38/3 (1997), pp. 513-537; Loma A. Rhodes: Emptying Beds. The Work of an Emergency Psychiatric Units, Berkeley 1991.

13 Berg / Bowker: The Multiple Bodies.

14 By treatment documents, she is referring to his ongoing and future medical treatment. In other words, it contains documents from his medical therapeutic journey.

15 Various research studies and government reports estimate the organised sector to be between $6 \%$ and $15 \%$ of the total labour force.

16 I use the term sartefacts in its scientific context as something observed in a scientific investigation or experiment that is not naturally present but occurs as a result of a preparative or investigative procedure. For example, »the curvature of the surface is an artefact of the wide angle view«. Or, at The Institute, "pain is located within a medical grid of habitats, and shifts in bodily dispositions".

Matthew Hull's "graphic artefacts" and Elaine Scarry's "artifact" are specific deployments of the word and I am not using these in the same sense though there are obvious overlaps and resonances given that one is writing about a semiotics of objects crafted through inscriptive practices in bureaucratic regimes, and the latter is discussing the central role pain plays in the making of objects and bodily substantiation that underlies production of all artefacts including scriptures (inscriptions). Both are important influences in the writing of this paper.

17 Desjarlais: Shelter Blues.

18 He writes that experience refers to "an inwardly reflexive, hermeneutically rich process that coheres through time by way of narrative« (Desjarlais: Shelter Blues, p. 17). Spatially, »to experience is to move through a landscape at once physical and metaphoric" (Desjarlais: Shelter Blues, p. 20). Temporally, it is marked with coherence and meaning. The units of experience, therefore, include a reflexivity, the emergence of a narrative about the events and activities that the person has lived through, and are also marked by coherence and meaning. "The gist of experience is that it goes beyond the situation at hand, with past, present and future mutually determining one another as parts of a whole» (Desjarlais: Shelter Blues, p. 22). Since a phenomenology of mentally ill in Boston did not 
coincide with such a conception of sexperience`, Desjarlais proposed "struggling along". He describes struggling along as proceeding "with great difficulty while trying at times to do away with or avoid constraints and hazards strewn in one's path « (Desjarlais: Shelter Blues, p. 19). It is largely a "sensorial mode of awareness which relies on forces of contingency, expediency, equilibrium and stasis" (Desjarlais: Shelter Blues, p. 22). The body does not move through a "landscape at once physical and metaphoric « and does not journey but is instead oriented to "pacing «, to an »episodic « living in which a narrative, coherence and meaning are absent, and which is marked with immediacy.

19 The exact word that is used in Kolkata is a "Khata", a word which is closer in meaning to an account book, a ledger or register rather than a file. It is an apt name since the BHT records within itself all the transactions that occur between the body, its disease and medicine's diagnostic and therapeutic attempts. It is an account of every shift in the body.

20 Berg / Bowker: The Multiple Bodies. For more on documentary productions in bureaucratic and legal worlds, refer to Ilana Feldman: Governing Gaza. Bureaucracy, Authority, and the Work of Rule, 19171967, Durham 2008; Akhil Gupta: Red Tape. Bureaucracy, Structural Violence and Poverty in India, Durham 2012; Matthew S. Hull: Ruled by Records. The Expropriation of Land and the Misappropriation of Lists in Islamabad, in: American Ethnologist 35/4 (2008), pp. 501518; Matthew S. Hull: The File. Agency, Authority and Autography in a Pakistan Bureaucracy, in: Language and Communication 23 (2003), pp. 287-314; McKay: Documentary Disorders; Annelise Riles: Documents. Artifacts of Modern Knowledge, Ann Arbor 2006: Cornelia Vismann: Files. Law and Media Technologies (transl. by Geoffrey Winthrop-Young), Stanford 2008; Max Weber: Economy and Society. An Outline of Interpretive Sociology, New York 1968. On medical documentation and its intersections with law, Lorna Rhodes provides an ethnographic account of subversive practices adopted by medical experts in their daily work; Lorna A. Rhodes: Emptying Beds. The Work of an Emergency Psychiatric Units, Berkeley 1991.

21 Ramah McKay demonstrates how documentary practices multiply authority as "a range of institutions, actors and agencies take on the governmental work of medical regulation « (McKay: Documentary Disorders, p. 546).

22 The term "world" is used here in its phenomenological meaning. Edmund Husserl describes »life-world" as the world of our common, immediate, lived experiences. It is also the world of our everyday lives in which we act sthrough our bodies. Edmund Husserl: The Crisis of European Sciences and Transcendental Phenomenology, Evanston 1954

23 Livingston: Improvising Medicine; Desjarlais: Body and Emotion.

24 Joanna Bourke's essay on gestures explores these non-verbal expressions of pain in detail. She writes of the body as a »semiotic instrument«, of pain's gestures as expressions of pain, as performances and as a "component of communication«. They may "spunctuater speech, but they also complement, enhance, replace or serve as alternatives to speech«. Joanna Bourke: The Story of Pain. From Prayer to Painkillers, New York 2014, pp. 159-192, at p. 160.

25 Habitus can be understood as bodily dispositions and techniques. Rachel Prentice: Bodies in Formation. An Ethnography of Anatomy and Surgery Education, Durham 2013; Pierre Bourdieu: The Logic of Practice, (trans. R. Nice), Stanford 1992; Marcel Mauss: Techniques of the Body, in: Economy and Society 2/1 (1973), pp. 70-88.
27 Ibid., p. 74.

28 An example of such medical semiotics are facial pain scales such as the Wong Baker Faces Pain Scale.

29 I was struck by Manoj Singh's complaint: he did not talk about difficulties at work as other patients did nor about pain as an ailment but about the difficulties it introduces in completing tasks at home. Since his jute mill has been closed for over a year, the limits pain has introduced in his familial obligations and everyday responsibilities have brought him to the Institute seeking therapy.

30 Photograph is the word commonly used for X-ray, CT and MRI scan images since these are printed and carried on photographic film.

31 A Trigger Point is a hyperirritable spot, a palpable nodule in the taut bands of the skeletal muscles' fascia. Direct compression or muscle contraction can elicit jump sign, local tenderness, local twitch response and referred pain which usually responds with a pain pattern distant from the spot. For more information, see: https://www.physio-pedia.com/Trigger_Points (17. 10. 2019)

32 She raises each leg upwards without bending it at the knee (SLR Straight Leg Raise test). She picks up his left leg, bends it at the knee and pushes the knee towards his right hip then she repeats with the other side (FADIR - Flexion Adduction Internal Rotation test). She hooks his big toes with her index fingers and asks him to pull the toes towards himself while she exerts pressure to move them in the opposite direction (EHL - Extensor Hallucis Longus test). And finally, she straightens his left leg, bends it and moving his knee outwards, places his left foot above the right knee. Then placing her left hand on his right hip and her right hand on his left knee she pushes them downwards, Manoj Singh cries out in pain. She repeats with his right leg and he does not react to the pressure or movement (FABER Flexion Abduction and Forward Rotation). For more: https://www. physio-pedia.com/ (17. 10. 2019).

33 Underlying the recognition of altered gait are assumptions of normal and pathological gait. As Georges Canguilhem describes, medical science is normative. Therapeutics is an effort in crafting a movement from a pathological form of life to the normal. Such understandings of normal and pathological gait are implicit in Dr. Ghosh's descriptions and it proved to be an insurmountable challenge as they tried to produce these forms through their research. Georges Canguilhem: On the Normal and the Pathological (trans. Carolyn R. Fawcett), The MIT 2007 [1966].

34 Dr. Ghosh's interest in such bodily dispositions has led to the development of the Gait Analysis Lab which the Institute is running in collaboration with biomechanical Engineers at a university in Kolkata. In the absence of inexpensive and reliable MRI scans, gait analysis is being explored as a viable diagnostic option.

35 These therapeutic inscriptions may take the form of pharmacological, surgical or physiotherapeutic interventions.

36 C. Nadia Seremetakis: The Ethics of Antiphony. The Social Construction of Pain, Gender, and Power in the Southern Peleponnese, in: Ethos 18/4 (1990), pp. 481-511. The anthropologist Veena Das has demonstrated such a relationship between pain and language in her 2007 essay, "Language and the Body: Transactions in the Construction of Pain«. Departing from Scarry's separation between bodies in pain and language of pain (or communicative acts of pain), Das shifts the focus to transactions between bodies in pain and language. She draws our attention to anthropological writings on the labour of mourning, most notably Nadia Seremetakis's work in which Seremetakis studies scenes of mourning and focuses on the work performed by acoustic and corporeal means in mourning by women in Inner Mani, Southern Peloponnese society. She describes it as an »iconography of the body that links sscreaming, 
open wounds, and the labor task of bearing pain « in childbirth, agricultural work and in mourning (Seremetakis: The Ethics of Antiphony, p. 502). She argues that this iconography "forms a symbolic continuum « between bodies in pain, bodily gestures and sounds. Das relies on these ethnographic links between bodies in pain, their acoustic worlds and efforts at truth production to explore transactions that occur between bodies in pain and language and draws from these social constructions of pain.

37 Roma Chatterji argues for such intercorporeal engagements in her 1998 paper »An Ethnography of Dementia«. Citing Mead, she describes how the self can be understood through an intersubjective engagement which is intercorporeal and how this underlies access to another's subjectivity. She writes, "the intersubjective process of self formation is essentially cognitive - not in the sense of a recognition of a law or of a universal principle but rather as a set of bodily dispositions which constitute these anticipatory structures of meaning. Thus, intersubjectivity assumes intercorporeality. Access to the other's subjectivity as a set of stable disposition, relating to the environment«. Chatterji: An Ethnography of Dementia. A Case Study of an Alzheimer's Disease Patient in the Netherlands, in: Culture, Medicine and Psychiatry 22 (1998), pp. 355-382, at p. 374.

38 Michel Foucault: The Birth of the Clinic. An Archaeology of Medical Perception (trans. A.M. Sheridan-Smith), London 2012 [1963].

39 Gupta: Red Tape; Vismann: Files; Mol: The Body Multiple.

40 Chatterji: An Ethnography of Dementia.

41 Ibid., p. 371.

42 Ibid.

43 Ibid., p. 368.

44 Ibid., pp. 368-369.

45 Ibid.

46 Desjarlais: Shelter Blues.

For a detailed understanding of how files in South Asia do not unify things narratively and are more a collection of different things with very little unity, refer to Matthew Hull: Hull: The File; Matthew S. Hull: Government of Paper. The Materiality of Bureaucracy in Urban Pakistan, Berkeley 2012. I discuss difficulties in medical coordination for pain's records below (pp. 14-15).

47 Ramah McKay's fieldwork at a clinic in Maputo where "processos" (patient files) worked as "a key technology in the constitution of medical subjects« and »came to stand in for clinical evaluation« (McKay: Documentary Disorder, pp. 549-551). While many features overlap between the Maputo clinic and this Institute in Kolkata, she does not recount a transfer of voice and subject to paper in medical documentation. Instead, her work focuses on plurality of medical governance, a result of multiple documentary practices at work. For more on documentary constitutions of a subject, see Ian Hacking: Making up People, in: Mario Biaglioli (ed.): The Science Studies Reader, New York 1999, pp. 161-171; Ian Hacking: Rewriting the Soul. Multiple Personalities and the Sciences of Memory, Princeton 1995.

48 The routine course of pain medicines at the Institute comprises of paracetamol (NSAID), gabapentin (anticonvulsant medication) and amitryptyline (medication for mood and anxiety disorders). In exceptional circumstances, tramadol (opioid) may also be prescribed.

49 Mol: The Body Multiple.

50 Alice Street: Artefacts of Not-Knowing. The Medical Record, the Diagnosis and the Production of Uncertainty in Papua New Guinean Biomedicine, in: Social Studies of Science 41/6 (2011), pp. 815-834. Alice Street writes of a similar process where uncertainty emerges out of multiplicity in Papua New Guinea. "[D]iagnostic uncertainty [was] not rendered problematic [but gave] rise to new forms of medical expertise and practice« (at p. 815). By maintaining diagnostic uncertainty at PNG, chances of survival and assignment of blame in the case of death were managed. In Manoj Singh's case at the Institute, on the other hand, the uncertainty is neither about disease (chronic pain) nor afflicted bodily habitat (neck). Instead, it has come into being because of pain, a condition that affectively exceeds and is multiple. The challenge this multiplicity poses is one of choosing a therapeutic course of action. In both centres, clinicians privilege "not 'What does this patient have? but ,What can we do?« (Street: Artefacts, p. 825). In Papua New Guinea, this leads to following all possible therapeutic courses of action for increasing patients' chances of survival while at the Institute it gives rise to more and more documentary productions and diagnostic attempts since a diagnosis is expected to reveal the pathophysiological processes underlying chronic pain. A diagnosis helps physicians plan therapeutic interventions.

51 Bruno Latour: Pandora's Hope. Essays on the Reality of Science Studies, Cambridge 1999, pp. 24-79.

52 Manoj Singh underwent two more periods of admission during my fieldwork - in March and August 2016 - and visited the OPD clinic every 2 weeks for his reviews and refills. 


\section{Abstract}

The Institute for Pain Management in Kolkata, like other modern institutions, is organised by record keeping. But the central object of its records, pain, presents a fundamental challenge to documentation. Pain is marked by a non-relational attribute that limits attempts to communicate and express it. I follow the institutional life of one patient and his struggles with health care through his documentary productions. As the paper traces clinical management of his pain, a proliferation of medical records is revealed. The forms of this documentary multiplicity, its materiality and how it enacts pain's therapeutics are described. The challenge of pain's communication is addressed by translating a body in pain constituted through artefacts and intersubjective relationships to a body in pain that exists almost entirely on paper. This translation proves efficacious in the eyes of doctors and patients, and is critical to the management of chronic pain in Kolkata.

\section{About the Author}

Shagufta Kaur Bhangu is a PhD candidate in sociology at Shiv Nadar University, India. Her ongoing doctoral research is ethnographic in nature and is a study of pain medicine's emergence in India. She has been investigating linguistic modes and epistemic practices in biomedicine to understand constitutions of pain as a medical object. 